\title{
DEMOCRACIA PARTICIPATIVA E JUVENTUDE POLITIZADA: estudo bibliométrico sobre os periódicos brasileiros de políticas públicas de juventude ${ }^{\mathrm{i}}$
}

\author{
Frederico Ramos Oliveira \\ Instituto Brasileiro de Informação em Ciência e Tecnologia \\ freddroliveira@gmail.com \\ Janinne Barcelos \\ Instituto Brasileiro de Informação em Ciência e Tecnologia \\ janinnebarcelos@gmail.com \\ Luana Melody Vasconcelos Brasil \\ Instituto Brasileiro de Informação em Ciência e Tecnologia \\ luana.melodybrasil@gmail.com \\ Priscila Rodrigues Santos \\ Instituto Brasileiro de Informação em Ciência e Tecnologia \\ cilaa.rodrigues@gmail.com \\ Milton Shintaku \\ Instituto Brasileiro de Informação em Ciência e Tecnologia \\ shintaku@ibict.br
}

\begin{abstract}
Resumo
As políticas públicas de juventude (PPJ) são um tema essencialmente multidisciplinar, cujas discussões em âmbito federal acontecem na Secretaria Nacional de Juventude, em parceria com os ministérios. A diversidade de definições conceituais e a transversalidade com a qual o tema é tratado torna complexa a tarefa de determinar os principais periódicos que discutem as PPJ, já que estes podem ser vinculados a diferentes disciplinas e instituições. Assim, o objetivo do presente estudo é levantar os periódicos indexados no DOAJ, Google Acadêmico, SciELO e Scopus que formam o núcleo de publicações sobre o tema. Trata-se, portanto, de um estudo que alinha os preceitos da Biblioteconomia, especialmente aqueles envolvidos na formação de bibliografias especializadas. Os resultados revelaram que as disciplinas de saúde, educação e psicologia publicam mais artigos sobre o tema, o que ratifica a multidisciplinaridade do estudo sobre as PPJ. Revela também tratar-se de um campo fértil para estudos, por sua amplitude, oportunidades para várias pesquisas e periódicos para publicação.
\end{abstract}

Palavras chave

Políticas de Juventude. Periódicos científicos. Secretaria Nacional de Juventude.

\section{INTRODUÇÃO}

Entende-se por democracia participativa o modelo político semidireto que aproxima os cidadãos das discussões da arena política, oferecendo a eles espaços em que possam legitimar opiniões e questões de relevância para a construção da agenda e das tomadas de decisão no Congresso Nacional e no Poder Executivo (SECRETARIAGERAL DA PRESIDÊNCIA DA REPÚBLICA, 2014). Considerada uma alternativa às democracias representativas, a democracia participativa preserva o papel do Estado como instrumento regulador das políticas públicas, contudo, busca dirimir a dicotomia entre representantes e representados através da participação efetiva dos cidadãos na vida pública (SELL, 2006).

Uma democracia que se diga participativa coloca em prática o princípio máximo da democracia - de que todo poder emana do povo - ao considerar os cidadãos como protagonistas da governabilidade. Dessa maneira, este modelo fomenta a participação de todos, estimulando maior 
interação entre governo e sociedade. Para efetivar a democracia participativa, são utilizados mecanismos que buscam o engajamento da população nas questões políticas locais e nacionais por meio de referendos, plebiscitos, iniciativa popular de leis, audiência pública, conselhos municipais, orçamento participativo e consultas públicas (MEDEIROS, 2014).

$\mathrm{Na}$ Constituição de 1988, a participação social é considerada como uma maneira de fortalecer o sistema de governança brasileiro em diversos artigos. Esta assegura o direito ao exercício da cidadania ativa pela garantia, por exemplo, da ação popular e da ação civil pública. Para se ter uma ideia, os artigos 10 e 204, respectivamente, defendem "a participação dos trabalhadores e empregados nos colegiados dos órgãos públicos" e "a participação da população por meio de organizações representativas, na formulação das políticas e no controle das ações em todos os níveis" (BRASIL, 2015). Isto é, a Constituição sugere que a cidadania transcenda o momento de votação nas eleições e seja aplicada socialmente na colaboração do espaço público, na discussão de novas leis e deliberação sobre demandas de políticas públicas.

Ao permitir maior participação da sociedade civil organizada, o poder público abre espaço para o estabelecimento de uma relação com benefícios mútuos, na qual o poder público pode adquirir maior credibilidade perante a população, e a população tem a possibilidade de influenciar nos espaços de discussão de políticas públicas e nos processos de decisão sobre como melhorar as comunidades à sua volta (MEDEIROS, 2014). Contudo, para que as experiências de democracia participativa obtenham êxito, é preciso, em primeiro lugar, que as administrações públicas criem canais de conexão e interação com a sociedade civil e, em seguida, que a população seja politizada o suficiente para opinar e agir sobre os direitos e deveres de natureza política e social.

No Brasil, país cuja pirâmide etária expressa uma população jovem (IBGE,
2016), a juventude sempre teve papel preponderante nas iniciativas de participação social, possivelmente porque é nessa faixa etária que se encontra a parte da população brasileira atingida pelos piores índices de desemprego, evasão escolar, falta de formação profissional, mortes por homicídio, envolvimento com drogas e com a criminalidade (WAISELFISZ, 2016). Tamanha sua expressividade dentro do cenário nacional, esse segmento conquistou, em 2005, uma Política Nacional de Juventude (PNJ), a instalação de um Conselho e criação da Secretaria Nacional de Juventude (SNJ), vinculada diretamente à Presidência da República (PR).

No entanto, mais do que perceber o jovem como sujeito social, é necessário entender que ele tem um papel fundamental na construção de um país: é pela juventude que a sociedade percebe o novo, vê-se questionada e depara-se com novos desafios, sendo convidada (e muitas vezes obrigada) à transformação. Composta por mais de 50 milhões de pessoas entre 15 e 29 anos, segundo o censo de 2010 do Instituto Brasileiro de Geografia e Estatística (IBGE), a juventude brasileira "representa o futuro em uma perspectiva de formação de valores e atitudes das novas gerações" (SPÓSITO; CARRANO, 2003, p. 17).

Dada sua relevância para o desenvolvimento social do país como um todo, faz-se necessário estar atento ao processo de formação da consciência política desses jovens e à conformação de novas políticas que colocam o jovem como sujeito capaz de refletir e agir sobre a própria história. Como defendem Spósito e Carrano (2003) " [...] as políticas públicas de juventude não seriam apenas $\mathrm{o}$ retrato passivo de formas dominantes de conceber a condição juvenil, mas poderiam agir, ativamente, na produção de novas representações" para toda a sociedade. Dessa forma, as PPJ devem permear, não só os discursos governamentais e sociais, como, também, as discussões acadêmicas.

Por essa razão, acredita-se na necessidade de conhecer os periódicos que abordam estas questões e com isso, 
contribuir com os pesquisadores e gestores que atuam nessa temática, tanto para publicar os estudos, quanto ter uma bibliografia especializada confiável. Nesse contexto, o presente estudo tem por objetivo elencar os periódicos que tratam de PPJ, destacando o núcleo de publicações indexadas sobre esse tema. Para tanto, foi realizada uma análise cientométrica nas bases Directory of Open Access Journals (DOAJ), Base de Dados em Ciência da Informação Acervo de Publicações Brasileiras em Ciência da Informação (Brapci), Scientific Electronic Library Online (SciELO) e Scopus. Para trazer um embasamento mais aprofundado sobre as questões em torno das PPJ em sociedades democráticas, nas próximas seções serão desenvolvidas discussões sobre politização da juventude e políticas públicas.

\section{JUVENTUDE POLITIZADA}

Em linhas gerais, entende-se por politização o processo de formação de opinião e consciência sobre as relações de poder de uma determinada sociedade, incluindo sua capacidade de compreender os mecanismos do pensamento e da ação política, assim como os deveres e os direitos dos cidadãos. Contudo, em tempos de crise de representatividade, esta compreensão do termo tem sido alargada para o que Arnaud e Guionnet (2005, p. 12-15) chamam de "novos terrenos de politização" com seus diversos modos de ação e engajamento.

Para os autores, esses terrenos tratam do amadurecimento dos cidadãos para além do processo eleitoral e da percepção dos canais de democracia participativa como escolas de cidadania capazes de colocar a sociedade em contato direto com a política. Os novos terrenos ampliam, portanto, a formação de opinião e a participação política, que não se restringem a meios tradicionais como sindicatos, militantismo, movimentos sociais, partidos políticos, campanhas políticas e período eleitoral.

Isso significa que o ato de votar e o direito de ser votado por si só não garantem, de modo algum, um comprometimento maior com as lutas de transformação social. Como alerta Castro (2008), as experiências de participação política podem ser estimuladas na medida em que esses sujeitos participam de situações de construção de espaços comuns de negociação e de luta. "Justapondo ideais de transformação do presente com os de reparação social, ambos podendo ser concebidos como reordenações do vínculo com o social e permitindo ao jovem o compromisso com o destino comum" (CASTRO, 2008, p. 266).

No Brasil, ainda que a inclusão da juventude nos debates políticos seja vista como um dos desafios da democracia, é possível notar que essa questão ganhou contornos especiais com as manifestações ${ }^{1}$ de junho de 2013 - quando milhares de pessoas, na maioria jovens ${ }^{2}$, foram às ruas numa iniciativa social que há muito não se via. Da configuração dos protestos, o que mais chamou a atenção de intelectuais e da mídia foi a falta de lideranças tradicionais, como membros de movimentos sociais consolidados, sindicalistas ou políticos (KRIGER, 2014). Além disso, foram protestos organizados majoritariamente via redes sociais, revelando que esse é um campo fértil para a análise da formação de opinião política dos jovens brasileiros.

As manifestações de 2013 representam um discurso de crítica às instituições políticas brasileiras e a vontade de transformação política do país por jovens atentos aos problemas locais, à má

1 Também conhecidas como protestos do Movimento Passe-Livre, as manifestações tiveram início em 2013, em São Paulo, quando discutia-se o aumento do preço das passagens de ônibus. Nesse período, a tarifa da passagem de ônibus sofria, no estado de Goiás, um aumento do valor de $\mathrm{R} \$ 2,20$ para o acordo final de $\mathrm{R} \$ 2,80$.

${ }^{2}$ De acordo com enquete produzida e divulgada pelo Instituto Datafolha na época dos protestos de 2013, o perfil formado pela maioria dos manifestantes era de pessoas com menos de 30 anos que frequentavam a universidade e que participavam de protestos de cunho político pela primeira vez. Disponível em: $<\underline{\text { http://datafolha.folha.uol.com.br/opiniaopublica/2 }}$ 013/06/1297654-largo-da-batata-reuniu-75-mil-amaioria-novatos-na-onda-de-protestos.shtml $>$. Acesso em: 12 dez. 2017. 
representação democrática, à violência, ao desemprego, à educação e à saúde. Nesse cenário, os jovens têm se mostrado cada vez mais preocupados com o coletivo e com temas que dizem respeito a mudanças sociais compreendidas como necessárias (KRIGER, 2014). Também nota-se a participação política não convencional, isto é, os "modos de expressão política alternativos", com o envolvimento dos jovens em torno de causas ambientais, culturais, comunitárias, religiosas, políticas, etc. Como explicam Brenner e Carrano (2008, p. 67):

[...] os jovens, ao contrário do que insinua o senso comum, não são desinteressados da participação na vida pública. $O$ que é fato, contudo, diagnosticado por diferentes investigações no Brasil e em outros países, são as mutações nas formas e conteúdos da participação motivadas pelas novas configurações sociais que interferem nas motivações e condições objetivas que favorecem ou inibem os processos de participação.

Nesse sentido, em contexto diferente dos jovens das Diretas e das Primaveras pelo mundo, a atual juventude brasileira tem construído novos caminhos para superar as limitações dos mecanismos tradicionais de participação democrática. Não significa, porém, que os elementos tradicionais da democracia (partidos, Congresso, militantismo, sindicatos, sistema de representatividade) estejam obsoletos, mas apenas que há outros elementos consideráveis para se atentar no processo de politização da juventude brasileira das duas últimas décadas. "Porque se, por um lado, é preciso avançar no processo de institucionalização da participação (o que assegura a continuidade além dos governos), por outro, é preciso estar sempre aberto ao novo" (BRASIL, 2014, p. 85).

De acordo com Brenner e Carrano (2008), as representações mais marcantes sobre o jovem na contemporaneidade são as manifestações artístico-culturais (individuais e coletivas). Para os autores supracitados:
[...] são os jovens envolvidos em tais práticas que possuem maior visibilidade na esfera pública e que orientam a busca ou produção de sentidos simbólicos, estilos, identidades coletivas e atitudes sociais compartilhadas [dando] visibilidade a graves problemas sociais vividos por moradores de espaços populares das cidades brasileiras (BRENNER; CARRANO, 2008, p. 68).

Não obstante, a internet tem se tornado um espaço de participação, interação e mobilização política da juventude. Dessa forma, os jovens vêm ganhando voz, também, através das redes sociais, de petições online, do compartilhamento de informações políticas que antes estavam sob domínio apenas da indústria da comunicação e dos ambientes virtuais de discussão e interação política (MEDEIROS, 2014).

De qualquer modo, vale ressaltar que para que esse engajamento e essa energia sejam aproveitados em prol da nação é preciso que os jovens se insiram nos processos de formulação, decisão e implementação de PPJ. Isto é, a participação política do jovem deve influenciar de forma efetiva as políticas locais, regionais, nacionais e internacionais, com capacidade para impactar na agenda pública, na participação legal do sistema representativo (a partir do voto), nas campanhas, nas eleições, na estrutura legislativa, nas pautas dos atores políticos e institucionais dos governos.

\section{POLÍTICAS PÚBLICAS DE JUVENTUDE}

Em um estado democrático, as políticas públicas orientam as ações governamentais. Lima (2012), em análise multifacetada das políticas públicas, destaca que são resultados de construções coletivas, que afetam a vida cotidiana da sociedade a qual atuam. Nesta mesma linha, Souza (2006), numa visão mais social, defende que as políticas públicas atuam na identificação e solução de problemas. 
Para Derani (2004) as políticas públicas podem avaliar o grau de desenvolvimento da sociedade, na medida em que representam as orientações que interferem nos comportamentos sociais. Quanto às PPJ, Ribeiro (2006) as considera como um conjunto de princípios, estratégias e ações que atendem às ansiedades dos jovens, em seus diversos contextos.

A atenção política e econômica dedicada à população jovem brasileira desde o início dos anos 2000 tem por base dois fatores: 1) a expansão do número de habitantes com idade entre 15 e 29 anos e 2) o aumento da população economicamente ativa, representando o que especialistas classificam a partir de 2010 como um "bônus demográfico"3. Segundo o último censo do IBGE, divulgado em 2010, os jovens correspondem a um quarto da população total do país, o que significa 51,3 milhões de habitantes.

Nesse contexto, surgem em profusão as políticas públicas voltadas para a juventude, no sentido de conceder direitos, proteção, lazer, inclusão, saúde, educação e trabalho, de acordo com a PNJ (BRASIL, 2006). A partir da compreensão de que os jovens demandam projetos e programas governamentais de atuação mais ampla e específica, em julho de 2005 foi criada a SNJ, vinculada diretamente à PR.

A percepção da necessidade da SNJ e seu apoio às PPJ é compartilhada por Lobato (2014), na medida em que a autora afirma que as PPJs atuam de forma intersetorial. Não apenas no Brasil essa afirmação encontra lastro: Afonso (2013) recorre ao Tratado de Maastricht, ${ }^{4}$ ressaltando que as PPJs são transversais e devem atuar nas necessidades dos jovens.

Como forma refinada de políticas públicas, as PPJ apresentam as mesmas complexidades, na medida em que a juventude apresenta-se de maneira multifacetada, com desafios a uma nação

\footnotetext{
3 Sobre o bônus demográfico brasileiro. Disponível em:

<http://www.ipea.gov.br/portal/images/stories/PD Fs/TDs/td 1528.pdf>. Acesso em: 12 dez. 2017. 4 Assinado pela União Européia em 1992.
}

também jovem no alcance de uma democracia que beneficie a população e desenvolva o país em sua totalidade.

\section{PROCEDIMENTOS METODOLÓGICOS}

Esta é uma pesquisa básica e descritiva, com abordagem mista, na medida em que coleta informações de forma quantitativa, as analisando qualitativamente, numa forma que Creswell (2007) denomina de pesquisa aninhada. Adota-se, também, algumas características do levantamento de bibliografia especializada, de acordo com preceitos e técnicas de pesquisa da Biblioteconomia.

Da mesma forma em que possui alguns aspectos relacionados à cientometria, na medida em que verifica a evolução científica de um tema, por meio dos resultados de pesquisa publicados em periódicos, por meio de indicadores bibliométricos. Com isso, assemelha-se a estudos, como de Santos (2003), no qual apresenta a importância dos estudos cientométricos e das publicações como fonte de dados.

Considera-se artigos publicados em periódicos brasileiros entre 2005 e 2017, disponibilizados em bases científicas como Brapci, DOAJ, Scopus e SciELO. Também foram considerados publicações indexadas no Google Acadêmico. Tal recorte temporal se justifica pela criação da SNJ, em 2005, que apresenta uma nova direção do Poder Executivo Federal nas políticas públicas para esta faixa etária. A realização da busca em diversas bases procura evitar possíveis distorções nos resultados e apresentar, com maior precisão, os periódicos que publicam textos sobre políticas da juventude.

Cada base tem exigências específicas para a indexação de periódicos, sendo que os critérios do Scopus e SciELO, por exemplo, demandam uma produção editorial muito mais criteriosa que o DOAJ. Assim, muitas revistas, principalmente das humanidades e ciências sociais, não são indexadas no SciELO e Scopus. Deste modo, a pesquisa envolveu também o 
DOAJ e o Google Acadêmico, a fim de identificar outros periódicos.

A estratégia de busca compreendeu a pesquisa pelos termos "juventude AND Secretaria Nacional da Juventude", "juventude AND políticas públicas", "juventude AND serviço público", "juventude AND políticas sociais", "juventude AND programas de juventude" e "juventude AND políticas públicas de juventude" nestas bases. Os resultados foram filtrados, de modo que se considerou apenas artigos publicados em periódicos brasileiros no período supracitado. Nas bases em que a filtragem automática não era possível, os artigos foram avaliados manualmente. A tabela 1 apresenta o número de artigos encontrados nas bases.

Tabela 1. Artigos encontrados nas bases, separados por termo de busca

\begin{tabular}{|c|c|c|c|c|}
\hline Juventude AND & $\begin{array}{c}\text { DO } \\
\text { AJ }\end{array}$ & $\begin{array}{c}\text { Google } \\
\text { Acadêmico }\end{array}$ & Scielo & Scopus \\
\hline Políticas públicas & 92 & 45 & 51 & 23 \\
\hline $\begin{array}{c}\text { Secretaria Nacional da } \\
\text { Juventude }\end{array}$ & 1 & 63 & 1 & 0 \\
\hline Serviço público & 5 & 2 & 3 & 0 \\
\hline Políticas sociais & 13 & 11 & 26 & 1 \\
\hline Programas de juventude & 37 & 1 & 18 & 0 \\
\hline $\begin{array}{l}\text { Políticas públicas de } \\
\text { juventude }\end{array}$ & 92 & 39 & 45 & 0 \\
\hline
\end{tabular}

Fonte: produzido pelos autores (2017)

Por fim, os artigos foram listados em planilha eletrônica, na qual se removeu registros duplicados. A próxima etapa da pesquisa envolveu a identificação dos periódicos, que procurava observar a quantidade de publicações sobre a temática e sua participação no total de artigos sobre PPJ. Também se realizou um comparativo entre as bases, a fim de identificar características específicas dos periódicos nelas indexados.

\section{RESULTADOS}

As PPJs são discutidas em 300 artigos, disponíveis em 192 periódicos. A maior parte das publicações se concentra em revistas da região Sudeste, o que pode ser explicado pelas características sócio históricas da ciência brasileira. Ademais, percebe-se maior interesse das disciplinas da área da saúde, educação e psicologia, nestas temáticas.

Cabe destacar que 21 (cerca de $11 \%$ ) revistas publicaram 100 artigos sobre o tema, o que representa 33\% dos artigos recuperados. Elas podem representar um núcleo de periódicos que publicam sobre as PPJ. Destas 21, 13 (6,7\% do total de revistas que discutem o tema) periódicos publicaram 73 artigos (24\% do total de artigos publicados sobre o tema). Dentre estes 13 periódicos com maior número de artigos publicados, $10(77 \%)$ são localizados na região Sudeste do país.

Com 10 artigos, a Ciência \& Saúde Coletiva é a revista com o maior número de publicações sobre o tema. A revista é mantida pela Associação Brasileira de Saúde Coletiva, está indexada no SciELO e 
apresenta o maior número de artigos recuperados nesta base. Com oito artigos cada, as revistas Saúde e Sociedade - mantida pela Associação Paulista de Saúde Pública e pela Universidade de São Paulo (USP) -, Educação e Pesquisa - também da USP -, e Ensaio: Avaliação e Políticas em Educação da Fundação Cesgranrio - também estão indexadas no SciELO.

As revistas Katálysis - de serviço social, mantida pela Universidade Federal de Santa Catarina (UFSC), Psicologia \& Sociedade - da Associação Brasileira de Psicologia Social - publicaram seis artigos sobre a temática, cada. $\mathrm{O}$ periódico Educação - da Pontifícia Universidade Católica do Rio Grande do Sul (PUCRS) contém cinco publicações, do mesmo modo que a revista Interface: Comunicação, Saúde, Educação - Universidade Estadual Paulista (Unesp).

Com quatro artigos publicados, estão as revistas Cadernos de Saúde Pública
- da Fundação Oswaldo Cruz -, Revista de Políticas Públicas - da Universidade Federal do Maranhão (UFMA)-, Cadernos CRH publicação de ciências sociais da Universidade Federal da Bahia (UFBA)-, ETD - Educação Temática Digital - da Universidade Estadual de Campinas (Unicamp) -, a Revista Íbero-Americana de Estudos em Educação - mantida pela Unesp e Universidad de Alcalá - e Fractal: Revista de Psicologia - da Universidade Federal Fluminense (UFF).

Quando se observa o ano de publicação dos artigos nestas 21 revistas com mais publicações, observa-se uma distribuição relativamente homogênea, o que aponta que os artigos encontrados não foram disponibilizados em dossiê específico. O gráfico 1 apresenta a quantidade de artigos sobre PPJ publicados por ano nas quatro revistas que mais discutiram o tema.

Gráfico 1. Quantidade de artigos sobre PPJ publicados por ano nas quatro revistas com maior produção

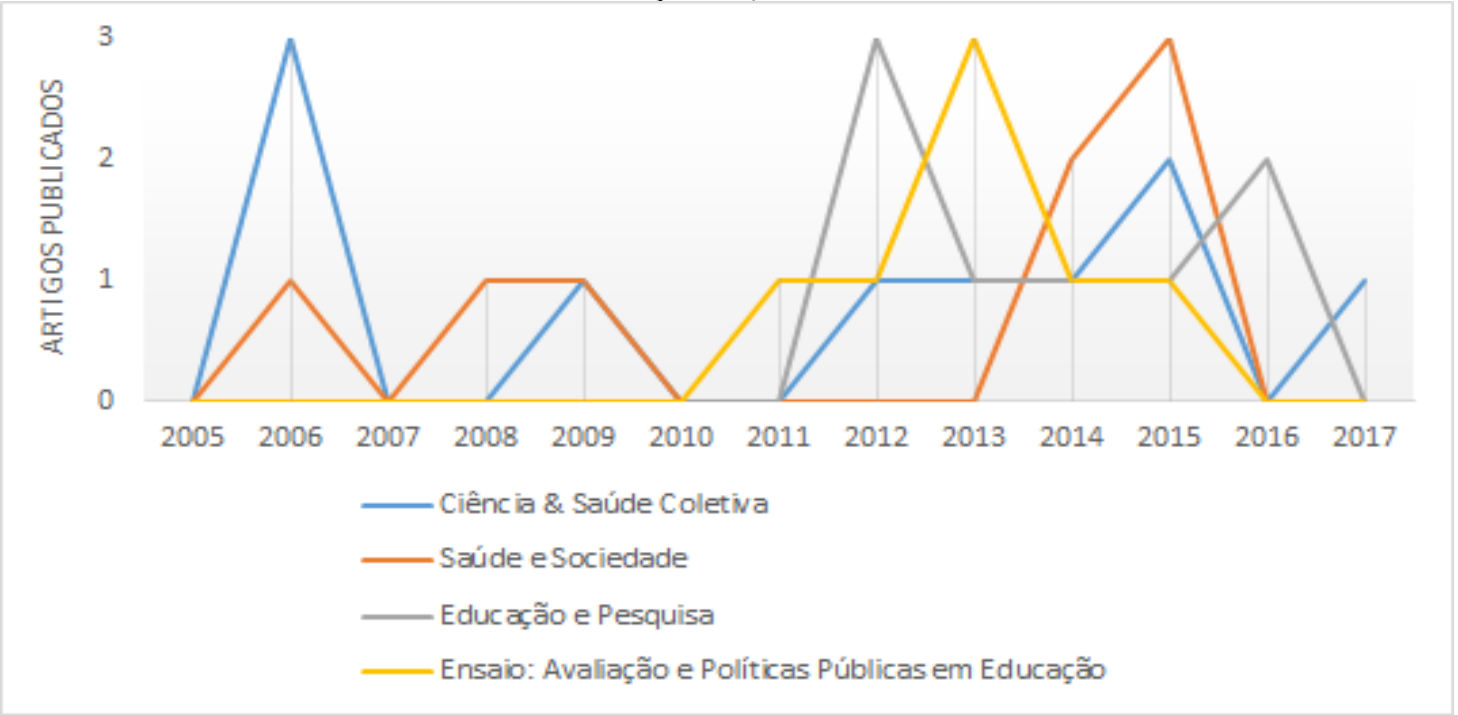

Fonte: produzido pelos autores (2017)

Se 21 periódicos concentram 33\% da produção acadêmica sobre PPJ, outras 30 revistas publicaram dois artigos cada sobre o tema, o que representa $20 \%$ da produção. Assim, quando se considera todas as revistas que publicaram pelo menos dois artigos sobre o tema, percebe-se que 51 periódicos
$(26,42 \%)$ respondem por $53 \%$ da produção já publicada sobre as PPJ.

As 142 revistas restantes são caracterizadas por terem publicado apenas um artigo, cada uma e respondem por $47,17 \%$ das publicações. É possível que se trate de uma publicação esporádica, ou que as bases e buscadores consultados não 
tenham indexado os demais artigos nelas publicado. É o que ocorre com a Revista Juventude e Políticas Públicas (RJPP), mantida pela SNJ. Com apenas uma edição, o periódico discute especificamente as PPJ e conta com 13 artigos já publicados. No entanto, apenas um foi recuperado a partir da estratégia de busca apresentada na metodologia. Ressalta-se que a referida revista não está indexada em grandes bases, o que dificulta a recuperação de artigos nela publicados.

Os resultados apontam, ainda, grande interesse das ciências da saúde, especialmente da saúde coletiva, na discussão da juventude e PPJ. As publicações desta área envolvem estudos epidemiológicos e de prevalência, bem como a efetividade de políticas públicas para a saúde desta faixa etária. Discutem, ainda, questões transversais, como a gravidez na adolescência, o consumo de drogas e o atendimento público à saúde.

A educação e a psicologia apresentam muitas publicações sobre a juventude, discutindo tanto os programas de governo e políticas públicas para esta faixa etária, como o próprio conceito de juventude e suas características no contexto escolar. Ainda se discute a inserção do jovem no mercado de trabalho, bem como sua participação política.

Destaca-se, neste sentido, o dossiê temático "Educação e Juventude", promovido pela revista Holos, periódico do Instituto Federal de Educação, Ciência e Tecnologia do Rio Grande do Norte (IFRN). A publicação deste dossiê resulta de concurso desenvolvido pela Secretaria de Educação Continuada, Alfabetização, Diversidade e Inclusão (Secadi - MEC), com a Fundação de Apoio à Pesquisa da

\subsection{DOAJ}

Em função de seus critérios de indexação, menos complexos que aqueles do SciELO e Scopus, o DOAJ reúne uma quantidade maior de artigos e, consequentemente, de publicações sobre a juventude. Algumas deficiências da base, no
Universidade Federal de Goiás (Funape UFG) e Associação Nacional de PósGraduação e Pesquisa em Educação (ANPEd). A seleção financiava a publicação de dossiês sobre temáticas específicas em revistas classificadas no escopo B2 a B4 no Qualis Periódicos. A revista Nuances: estudos sobre educação, da Unesp, também foi premiada e desenvolveu o mesmo dossiê.

Importa ressaltar, ainda, a presença de 17 artigos que discutem, diretamente, o Programa Nacional de Integração do Jovem (Projovem), em suas diversas ações. Destes, $14(82,35 \%)$ foram publicados em periódicos da educação. Estes textos foram publicados a partir de 2009 e, em 2012, o maior número de artigos por ano é publicada: foram 4 pesquisas relatadas em três revistas. Por outro lado, o Programa Nacional de Acesso ao Ensino Técnico e Emprego (Pronatec) é debatido em apenas dois artigos que não foram publicados em revistas desta área. Os artigos foram publicados, respectivamente, em 2013 e 2016.

A revista Adolescência \& Saúde, mantida pelo Núcleo de Estudos da Saúde do Adolescente da Universidade Estadual do Rio de Janeiro (UERJ), existe desde 2004 e já publicou 14 volumes, totalizando 53 números. Envolve, dentre os artigos publicados, discussões esporádicas sobre as políticas de saúde específicas para esta faixa etária. Cabe apresentar, ainda, a revista Segurança Urbana e Juventude, da Unesp, que, embora esteja descontinuada, publicou três volumes entre 2008 e 2011 - dois números em 2008, um em 2009, dois em 2010 e um, apenas, em 2011. Algumas edições desta publicação apresentam apenas artigos em espanhol, enquanto outras possuem textos em português e espanhol. entanto, exigem a checagem dos artigos, já que não há um sistema de busca tão refinado. Um exemplo destas deficiências é o fato que o mesmo artigo é recuperado, em alguns casos, duas vezes e com ordem de autoria diferente. Após esta etapa, foram recuperados 110 artigos na base.

Nesta base, a maior parte dos artigos recuperados foi publicada em 
periódicos da saúde (27 artigos, em nove revistas). Destacam-se as revistas Ciência \& Saúde Coletiva (8) e Saúde e Sociedade (7) e Interface: Comunicação, Saúde e Educação (4). Com 16 periódicos e 26 artigos, a educação Destacam-se os periódicos Educação (4), Educação e Pesquisa (3) e ETD - Educação Temática Digital (3). Por fim, ainda tem relevância a psicologia, com 11 artigos, distribuídos em oito periódicos.

\subsection{SciELO}

Entre os periódicos indexados pela base, 38 discutiram o tema em um total de 74 artigos publicados. No entanto, 25 $(64,10 \%)$ destas revistas têm apenas um artigo publicado sobre PPJ, o que pode ser uma publicação esporádica e que não é significativa para os objetivos desta pesquisa. Quatro revistas publicaram dois artigos sobre a temática, enquanto três periódicos foram responsáveis também por três publicações cada. As seis revistas restantes publicaram 32 artigos, o que representa 43\% do total de artigos sobre o tema indexados nesta base. Os resultados apresentados nesta seção destacam estes periódicos, que podem representar o núcleo de revistas indexadas no SciELO que disseminam informações sobre PPJ.

Os dois periódicos que se destacam por sua produtividade são da área da saúde e publicaram, cada um, sete artigos sobre o tema. São vinculados à Associação Brasileira de Saúde Coletiva (Abrasco) e à Associação Paulista de Saúde Pública (APSP), o que é digno de nota, já que a maior parte dos periódicos brasileiros é mantido por universidades. Verifica-se certo interesse em PPJ pelas disciplinas de Saúde, especialmente no que se refere a políticas de saúde para esta faixa etária.

Há, ainda, duas revistas, mantidas pela Universidade de São Paulo (USP) e, também, pela UFSC, com cinco artigos publicados em cada uma. A revista da USP é da área da educação, enquanto o periódico catarinense é de serviço social. Por fim, há ainda uma revista da UFBA - ciências humanas - e outra mantida pela Fundação
Cesgranrio - educação -, ambas com quatro publicações.

\subsection{Google Acadêmico}

O buscador indexa 156 artigos, distribuídos em 132 revistas. Destes, apenas um artigo foi recuperado em 113 periódicos. Entre as 19 revistas restantes, quatro publicaram três artigos e 15, dois artigos cada. Não se percebe, desta forma, uma publicação que concentra artigos sobre PPJ.

Há, contudo, uma questão a ser considerada: o Google Acadêmico é o único que recuperou artigos da RJPP, da SNJ. O periódico não está indexado em nenhuma base, o que dificulta sua recuperação. $O$ Google Acadêmico somente encontrou um artigo da revista. No entanto, o RJPP apresenta treze artigos que discutem, diretamente, as PPJ.

\subsection{Scopus}

É a base que recupera a menor quantidade de artigos (25) e periódicos (21). Cabe ressaltar que as políticas de indexação do Scopus são mais restritivas, o que explica este resultado. $\mathrm{Na}$ base, quatro revistas são responsáveis por $36 \%$ dos artigos indexados. São elas: Psicologia e Sociedade (3), Ciência e Saúde Coletiva (2), Ensaio: Avaliação de Políticas Públicas em Educação (2) e Physis: Revista de Saúde Coletiva (2). Observa-se, novamente, que a saúde, a educação e psicologia são, nesta ordem, as áreas que mais publicaram sobre as PPJ. Os 16 periódicos restantes publicaram um artigo, cada.

\section{CONSIDERAÇÕES FINAIS}

A partir dos resultados, observa-se que as PPJs são discutidas frequentemente em pelo menos 25 periódicos brasileiros. Há, ainda, publicações esporádicas em 143 revistas. Percebe-se grande discussão desta temática nas ciências da saúde, na educação e, também, psicologia. O direito e o serviço social, as ciências sociais aplicadas e humanas também abordam esta temática. 
Não se percebe, contudo, o debate sobre as PPJs em periódicos de ciências exatas e da terra ainda é incipiente.

Outro aspecto revelado pela pesquisa são os desafios enfrentados por revistas de menor porte, que não são indexadas por grandes bases. Esta questão dificulta a recuperação dos artigos já publicados, diminui a visibilidade da publicação e, consequentemente, torna mais esporádica a publicação de um artigo sobre a temática. Não se pode esquecer, ainda, que algumas publicações, como a Ciência \& Saúde Coletiva, publicam uma maior quantidade de números por ano, o que aumenta a possibilidade de existir um artigo sobre as PPJs. Neste sentido, cabe apontar que, em 2017, o periódico supracitado publicou 12 números.

Estes resultados destacam a necessidade de criar de políticas de fomento a revistas que discutam as PPJs, especialmente em áreas em que este tema não é publicado comumente. Além disto, sugere-se a criar de programas de apoio a estas publicações, que garantam sua continuidade e auxiliem sua qualificação. $\mathrm{O}$ dossiê "Educação e Juventude", produzido sob apoio da Associação Nacional de PósGraduação e Pesquisa em Educação (AnpED) e Secretaria de Educação Continuada, Alfabetização, Diversidade e Inclusão (Secadi), demonstra que é possível criar propostas de fomento eficientes e sustentáveis.

Em outra frente, a reativação da RJPP, mantida pela SNJ, seria interessante. Em sua única edição, o periódico publicou mais artigos sobre as PPJs que a revista Ciência \& Saúde Coletiva fez entre 2005 e 2017. Se não tivesse sido descontinuado, o periódico poderia ser referência como publicação especializada no tema.

\title{
PARTICIPATIVE DEMOCRACY AND POLITICIZED YOUTH: A BIBLIOMETRIC STUDY ON THE BRAZILIAN JOURNALS OF PUBLIC YOUTH POLICIES
}

\begin{abstract}
Public policies of youth (PPJ) are an multidisciplinary theme, whose discussions in Brazil's Executive branch take place in the National Youth Secretary, in partnership with ministries. Since there is a diversity of concepts and a transversality approach of the subject, it is difficult to determine the main Brazilian periodicals which discuss the theme, since these can be linked to different disciplines and institutions. Thus, the objective of this study is to assess which journals indexed in DOAJ, Google Scholar, SciELO and Scopus form a nucleus of publications on the topic. It is a study which uses methods of Librarianship, especially those involved in the formation of specialized bibliographies. The results revealed that the disciplines which publish more articles on the subject is health, education and psychology. It ratifies the existence of a multidisciplinary approach of the study of PPJ. It also reveals it as a field for studies, because of its breadth, opportunities for various researches and existence of periodicals for publication.
\end{abstract}

Keywords

Policies of youth. Scientific journals. National Secretariat of Youth. Artigo recebido em 18/01/2018 e aceito para publicação em 17/02/2018

\section{REFERÊNCIAS}

AFONSO, C. M. D. F. Política sociais europeias para a juventude: o programa Juventude em Acção em Portugal. 2013. 92 f. Dissertação (Mestrado) - Universidade Católica Portuguesa, Lisboa, 2013. Disponível em: $<$ http://repositorio.ucp.pt/bitstream/10400 $.14 / 11952 / 1 /$ Dissertação.pdf $>$. Acesso em: 10 out. 2017.
ARNAUD, Lionel; GUIONNET, Christine. Les frontières du politique: Enquête sur les processus de politisation et de dépolitisation. Rennes: Presses Universitaires de Rennes, 2005.

BRASIL. Constituição da República Federativa do Brasil 1988. 48. ed. Brasília: Câmara dos Deputados, Edições Câmara, 2015. 
. INSTITUTO BRASILEIRO DE GEOGRAFIA E ESTATÍSTICA. Plano de dados abertos 2016-2017. Brasília: IBGE, 2016. Disponível em: https://ww2.ibge.gov.br/home/disseminaca $\mathrm{o} /$ eventos/missao/Plano de Dados Abert os IBGE 20162017 20160831.pdf.

Acesso em: 10 out. 2017.

\section{SECRETARIA-GERAL DA} PRESIDÊNCIA DA REPÚBLICA. Participação Social no Brasil: entre conquistas e desafios. Brasília: SecretariaGeral da Presidência da República, 2014.

BRENNER, A. K.; CARRANO, P. Juventude: a arte do poder. Revista Proposta-FASE, v. 32, n. 115, p. 66-71, $\mathrm{jan} / \mathrm{mar} 2008 \quad-$ Disponível em: $<$ https://issuu.com/ongfase/docs/propost a 115 final $>$. Acesso em: 10 out. 2017.

CASTRO, L. R. Participação Política e Juventude: do mal-estar à responsabilização frente ao destino comum. Revista de Sociologia e Política, v. 16, n. 30, p. 253268 jun. 2008.

CRESWELL, John W. Projeto de pesquisa métodos qualitativo, quantitativo e misto. In: Projeto de pesquisa métodos qualitativo, quantitativo e misto. 2. ed. Porto Alegre: Artmed, 2007.

DERANI, Cristiane. POLÍTICA PÚBLICA E A NORMA POLÍTICA. Revista da Faculdade de Direito Ufpr, [s.l.], v. 41, p.19-28, 31 dez. 2004. Universidade Federal do

Parana.

http://dx.doi.org/10.5380/rfdufpr.v41i0.38 $\underline{314}$.

\section{MEDEIROS, A. M. Democracia participativa. Disponível em: $<\underline{\text { http://www.portalconscienciapolitica.com. }}$ $\mathrm{br} /$ ciber-democracia/democracia- participativa/>. Acesso em: 10 dez. 2017.}

KRIGER, Miriam. Politización juvenil en las naciones contemporáneas. El caso argentino. Revista Latinoamericana de Ciencias Sociales, Niñez y Juventud, Manizales, v. 12, n 2, p. 583-596, jul./dic. 2014.

LIMA, Waner Gonçalves. Política pública: discussão de conceitos. Revista Interface (Porto Nacional), Amapá, n. 5, p.49-54, out. $2012 . \quad$ Disponível em: < http://www.ceap.br/material/MAT26022 013171120.pdf $>$. Acesso em: 10 out. 2017.

LOBATO, Ana Laura (Org.). Jovens mulheres e políticas públicas. Brasília: Presidência da República, 2014.

SOUZA, Celina. Políticas Públicas: uma revisão da literatura. Sociologias, Porto Alegre, v. 8, n. 16, p.20-45, jul. 2006. Semestral. Disponível em: $<$ http://www.scielo.br/pdf/soc/n16/a03n1 6>. Acesso em: 08 out. 2017.

RIBEIRO, Eliane et al. Diálogo nacional para uma política pública de juventude. Rio de Janeiro, São Paulo: Ibase. Pólis, 2006.

SELL, Carlos Eduardo. Introdução à Sociologia Política: política e sociedade na modernidade tardia. Petrópolis: Vozes, 2006.

SANTOS, Raimundo Nonato Macedo dos. Produção científica: por que medir? o que medir?. Revista digital de Biblioteconomia e Ciência da Informação, v. 1, n. 1, 2003.

SPÓSITO, M. P.; CARRANO, P. C. R. Juventudes e políticas públicas no Brasil. In: DÁVILA LÉON, O. (Org.). Políticas públicas de juventud en América Latina: políticas locales. Viña del Mar: CIPDA, 2003. Disponível em: $<$ http://www.scielo.br/pdf/rbedu/n24/n2 4a03 >. Acesso em: 13 nov. 2017.

WAISELFISZ, Julio Jacobo. Mapa da violência 2016: homicídios por armas de fogo no Brasil. Brasília: Secretaria Nacional de Juventude, 2016. 
Democracia participativa e juventude politizada: estudo bibliométrico sobre os periódicos brasileiros de políticas públicas de juventude

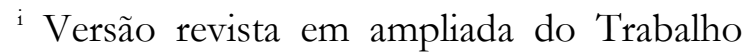
"Periódicos sobre políticas públicas de juventude" apresentado no evento ABEC MEETING, 6-9, novembro, Curitiba, PR, 2017. 